\title{
New Solvents for Cellulose. II. Ethylenediamine/Thiocyanate Salt System ${ }^{\dagger}$
}

\author{
Kazuyuki Hattori, ${ }^{\dagger \dagger}$ Emiko Abe, Takashi Yoshida, and John A. Cuculo* \\ Department of Applied and Environmental Chemistry, Kitami Institute of Technology, 165 Koen-cho, Kitami 090-8507, Japan \\ *Department of Textile Engineering, Chemistry, and Science, Centennial Campus, \\ Box 8301, North Carolina State University, Raleigh, NC 27695, U.S.A.
}

(Received September 1, 2003; Accepted November 17, 2003)

\begin{abstract}
The ethylenediamine/thiocyanate salt system was found to be a new solvent for cellulose. The solubility, dissolution behavior, solution properties, and cellulose recovered from the solutions were investigated. The dissolution took place at room temperature, and the maximum solubility achieved was $16 \%(\mathrm{w} / \mathrm{w})$ for cellulose of DP210 in the ethylenediamine/sodium thiocyanate $54 / 46(\mathrm{w} / \mathrm{w})$. The dependence of cellulose solubility on DP is also described. Tracing the dissolution behavior of the cellulose by $\mathrm{CP} / \mathrm{MAS}{ }^{13} \mathrm{CNMR}$ measurements revealed the polymorphic conversion of cellulose I to III to amorphous structure during the dissolution process. The cellulose dissolved was stable for 30 days storage at room temperature. Microscopic observations and steady-shear viscosity measurements of the solutions indicated mesophase formation of cellulose in the ethylenediamine/sodium thiocyanate system. This anisotrpoic phase appeared from $c a .10 \%$ (w/w) cellulose with DP210 and greatly depended on the cellulose concentrations. Coagulation studies disclosed that cellulose II and amorphous cellulose were recovered from the cellulose/ethylenediamine/thiocyanate salt solutions when water and alcohol were used as a coagulant, respectively. It was suggested that this solvent system has high potential for cellulosic fiber and film formations.

KEY WORDS Cellulose / Cellulose Solvent / Cellulose Solution / Amine / Thiocyanate / Dissolution Mechanism / Regenerated Cellulose /
\end{abstract}

Cellulose is a linear and high molecular weight polymer as well as a natural, renewable, and biodegradable material. However, due to its considerable inter- and intramolecular hydrogen bonds, cellulose neither melts nor dissolves readily in common solvents. The complicated crystalline and amorphous morphology has also been preventing cellulose from being exploited to its fullest potential. Any process which simplifies or hastens the dissolution of cellulose represents a significant step forward in the development of cellulose as a viable, ecologically favorable polymer source. Furthermore, the ability of cellulose and cellulose derivatives to form mesophase in certain solvents has resulted in attempts to develop high-performance cellulosic fibers and membrane. ${ }^{2}$

At present, there are a few solvents that can directly dissolve cellulose without heavy metal complexation and any chemical derivatization, which are lithium chloride/dimethyl acetamide (LiCl/DMAc) ${ }^{3} \mathrm{~N}$-methylmorpholine- $N$-oxide/water $\left(\mathrm{NMMO} / \mathrm{H}_{2} \mathrm{O}\right),{ }^{4}$ calcium thiocyanate/water $\left(\mathrm{Ca}(\mathrm{SCN})_{2} / \mathrm{H}_{2} \mathrm{O}\right),{ }^{5}$ etc. Quite recently, ionic liquids containing 1-butyl-3-methylimidazolium cations were discovered to dissolve high $M_{\mathrm{w}}$ pulp $(\mathrm{DP} \approx 1000)$ with $10 \%(\mathrm{w} / \mathrm{w})$ at elevated temperatures. ${ }^{6}$ However, almost known solvents still have some undesirable points, for example, chemical safety, environmental concern, degradation of cellulose, requirements of high temperatures and/or pretreatment of cellulose, poor mechanical properties of the cellulose recovered, and high cost for commercial use.

We have been studied new solvent for cellulose and found amine/salt systems to be a good solvent. The first one in this series is liquid ammonia/ammonium thiocyanate $\left(\mathrm{NH}_{3} / \mathrm{NH}_{4} \mathrm{SCN}\right)$ system. ${ }^{7}$ This solvent is prepared ${ }^{8}$ by dissolving $\mathrm{NH}_{4} \mathrm{SCN}$ into liquid $\mathrm{NH}_{3}$ so that a condensation process of the $\mathrm{NH}_{3}$ is required and care must be exercised to minimize its volatilization to avoid the subsequent crystallization of $\mathrm{NH}_{4} \mathrm{SCN}$. To overcome this problem, the use of other amines which possesses high boiling point was attempted instead of $\mathrm{NH}_{3}$, resulting that the hydrazine/sodium thiocyanate $\left(\mathrm{NH}_{2} \mathrm{NH}_{2} / \mathrm{NaSCN}\right)$ of composition of 52/48 w/w had high dissolution power for cellulose. ${ }^{1}$ However, hydrazine is, unfortunately, toxic and carcinogenic though much lower volatile than $\mathrm{NH}_{3}$, so the utilization is limited.

Besides the ability of dissolving cellulose, another interest of the cellulose solutions on the amine/salt solvent is mesophase formation. Due to the semi-rigidity of cellulose molecule, both cellulose solutions in the $\mathrm{NH}_{3} / \mathrm{NH}_{4} \mathrm{SCN}^{9-13}$ and $\mathrm{NH}_{2} \mathrm{NH}_{2} / \mathrm{NaSCN}^{1}$ sys-

\footnotetext{
${ }^{\dagger}$ For Part I, Reference 1.

${ }^{\dagger \dagger}$ To whom correspondence should be addressed (Tel: +81-157-26-9397, Fax: +81-157-24-7719, E-mail: hattori@chem.kitami-it.ac.jp).
} 
tems form liquid crystals dependent on cellulose concentration, cellulose DP, and temperature. Generally, an anisotropic cellulose solution such as liquid crystals gives high-performance cellulosic fibers and films with high strength and modulus after proper drawing and subsequent coagulation process. ${ }^{14}$

Thus, it is important to investigate not only the solubilization of cellulose but also the solution properties in a certain solvent. Here we report on the third solvent for cellulose in the series of amine/salt system, ethylenediamine/thiocyanate salt to realize a simple and convenient cellulose solvent. The physical and chemical properties of the cellulose solutions prepared by this solvent system are also discussed.

\section{EXPERIMENTAL}

\section{Solubility Measurements of Thiocyanate Salt in Ethyl- enediamine}

Prior to use, all thiocyanate salts except for $\mathrm{Ca}(\mathrm{SCN})_{2}$ were treated with the same procedure as described in the previous paper. ${ }^{1} \mathrm{Ca}(\mathrm{SCN})_{2}$ was obtained only as a tetrahydrate form through Wako Pure Chemical Industries, Ltd. It was converted into the anhydrous form by heating overnight at $110^{\circ} \mathrm{C}$ in vacuo. Anhydrous ethylenediamine was used without further purification.

Solubility measurements of the thiocyanate salts were carried out in a dry box filled with nitrogen to avoid moisture. A known amount of dried salt $(0.100 \mathrm{~mol})$ was placed in a $100 \mathrm{~mL}$ necked flask equipped with a magnetic stirrer tip and thermometer. The flask was attained to $25^{\circ} \mathrm{C}$ in a constant-temperature bath, then ethylenediamine was added dropwise onto the salt with stirring until the salt was completely dissolved, as observed visually. The solubility of the salt was determined from the weight ratio of the salt to the added ethylenediamine.

\section{Solubility Measurements of Cellulose in the Ethylene- diamine/Salt System}

Several cellulose samples were used for the solubility measurements. Cellunier P, which underwent a sulfite pulping process, was obtained from ITT Rayonier, Inc. From Cellunier P, two cellulose samples with different molecular weight were prepared according to the previous article. ${ }^{1}$ The average degree of polymerization $(D P)$ was calculated from Eq 1 using the intrinsic viscosity $[\eta]$ of the cellulose solution in $0.500 \mathrm{M}$ cuene (cupriethylenediamine hydroxide solution) applying the ASTM D1795 and D4243 methods. ${ }^{15,16}$

$$
D P^{\alpha}=[\eta] / K
$$

where $\alpha=1$ and $K=0.750 \mathrm{~cm}^{3} \mathrm{~g}^{-1}$. The average molecular weight $\left(M_{\mathrm{w}}\right)$ is readily able to be converted from the DP. The DPs of the cellulose prepared from Cellunier P (DP716) were 536 and 376. Microcrystalline Cellulose Powder CC41 (DP210) and bacterial cellulose (DP2250) were also obtained from Whatman Bio Systems and Biopolymer Engineering, Inc., respectively.

A known weight of cellulose was placed in a thick polyethylene bag $(13.5 \mathrm{~cm} \times 10 \mathrm{~cm})$. In a dry box filled with nitrogen, $10 \mathrm{~g}$ of the ethylenediamine solution saturated thiocyanate salt was added to the bag. After the removal of gas from the bag, the mixture was cooled to $-20^{\circ} \mathrm{C}$ for $1 \mathrm{~h}$ and then warmed to $50^{\circ} \mathrm{C}$ for $30 \mathrm{~min}$ together with intermittent shearing using a wooden roller. The mixture was subjected several times to this temperature cycling technique. ${ }^{17} \mathrm{By}$ increasing the cellulose concentration by $1.0 \%(\mathrm{w} / \mathrm{w})$ increments, the solubility of the cellulose was determined. The maximum cellulose solubility was considered to be the concentration observed just before the one exhibiting undissolved cellulose after 5 days. Judgment of the dissolution was performed by visual observation through a polarizing microscope with a Nikon ECLIPSE E400 POL under crossed polars.

\section{Solution Viscosity}

Relative viscosity of the cellulose solutions in the ethylenediamine/NaSCN 54/46 (w/w) was determined at the concentration of $1.00 \%(\mathrm{w} / \mathrm{v})$ of Cellulose Powder CC41 using an Ubbelohde type capillary viscometer at $25 \pm 0.1^{\circ} \mathrm{C}$.

Steady shear viscosity was measured by a Rheometrics DSR II cone and plate rheometer for non-dilute region ranged from 7 to $12 \%(\mathrm{w} / \mathrm{w})$ of the cellulose at $40 \pm 0.1{ }^{\circ} \mathrm{C}$. The cone angle and diameter were $0.04 \mathrm{rad}$ and $25 \mathrm{~mm}$, respectively. The gap between the cone and plate was set to $1 \mathrm{~mm}$. The shear rate was conducted to $1.0 \times 10^{-3} \mathrm{~s}^{-1}$.

\section{$C P / M A S{ }^{13}$ C NMR Measurements}

Dissolving process of cellulose in the ethylenediamine/NaSCN was monitored by means of ${ }^{13} \mathrm{C}$ NMR spectroscopy with cross polarization and magic angle spinning (CP/MAS) technique on a Bruker AM300 spectrometer operating at $75 \mathrm{MHz}$. For the rapid dissolution of cellulose, the temperature cycling method $^{17}$ was applied as follows:

1. Whatman CC41 cellulose powder was taken to the $\mathrm{CP} / \mathrm{MAS}{ }^{13} \mathrm{C}$ NMR measurement before dissolving.

2. In a polyethylene bag, Whatman CC41 cellulose (5 g) was dispersed in the ethylenediamine/ NaSCN 54/46 (w/w) (100 g), then mixed with intermittent shearing by a wooden roller at room temperature (sample 1). 
3. After $3 \mathrm{~h}$, a part of sample 1 was taken from the bag and filtered by forced filtration to remove the ethylenediamine/ $\mathrm{NaSCN}$ solvent and the cellulose dissolved. The residue was fully washed with water and recorded on the CP/MAS ${ }^{13} \mathrm{CNMR}$.

4. After $3 \mathrm{~h}$ storage of sample 1 at room temperature, it was cooled to $-20^{\circ} \mathrm{C}$ for $3 \mathrm{~h}$ (sample 2). A part of sample 2 was taken from the bag, warmed to room temperature quickly, and filtered by forced filtration. The residue was fully washed with water and then recorded on the $\mathrm{CP} / \mathrm{MAS}{ }^{13} \mathrm{C}$ NMR.

5. Another temperature cycling between room temperature and $-20^{\circ} \mathrm{C}$ was subjected to sample 2 (sample 3). A part of sample 3 was taken from the bag, received the same procedure, and was recorded on the $\mathrm{CP} / \mathrm{MAS}{ }^{13} \mathrm{C} \mathrm{NMR}$.

6. The same temperature cycling was imposed three times (sample 4), then, it was filtered, washed, and recorded on the $\mathrm{CP} / \mathrm{MAS}{ }^{13} \mathrm{C} \mathrm{NMR}$.

All CP/MAS ${ }^{13} \mathrm{CNMR}$ spectra were measured at room temperature using a double air-bearing probe and a zirconium oxide sample rotor. The MAS rate was $4000 \mathrm{~Hz}$. The data acquisition was performed with a standard $\mathrm{CP}$ pulse sequence using a $3.5 \mu \mathrm{s}$ ${ }^{1} \mathrm{H} 90^{\circ}$ pulse, $1 \mathrm{~ms}$ contact pulse, and $4 \mathrm{~s}$ delay time for 5000 scans. The chemical shift was referenced to 29.5 and $38.6 \mathrm{ppm}$ from tetramethylsilane by adamantane as an external standard.

\section{Infrared and Wide Angel X-Ray Diffraction Measure- ments}

Infrared (IR) spectra were obtained with a Shimadzu FT IR-8300 spectrometer using a $\mathrm{KBr}$ pellet method. Wide angle X-Ray diffraction (WAXD) measurements were performed on a Rigaku RINT1200 RAD diffractometer using $\mathrm{CuK}_{\alpha}$ radiation with $40 \mathrm{kV}$ of acceleration voltage and $30 \mathrm{~mA}$ tube current. The diffraction angles $(2 \theta)$ observed ranged from 10 to $30^{\circ}$ by $0.1^{\circ}$ intervals.

\section{Crossed Polars Microscopic Observations}

Mesophase formation of the cellulose solutions in the ethylenediamine/NaSCN was observed by using a Nikon ELIPSE E400 POL crossed-polars microscopy under cross nicol. It was equipped with an electrical hot stage and digital camera.

\section{RESULTS AND DISCUSSION}

\section{Solubility of Cellulose in the Ethylenediamine/Salt System}

In the early work, ${ }^{1,18,19}$ it was revealed that several inorganic salts such as $\mathrm{NH}_{4} \mathrm{SCN}$, LiSCN, NaSCN, $\mathrm{KSCN}, \mathrm{NaNO}_{3}, \mathrm{NaI}$, and $\mathrm{NH}_{4} \mathrm{I}$ were dissolved in liquid $\mathrm{NH}_{3}$ and $\mathrm{NH}_{2} \mathrm{NH}_{2}$ and that some of the solutions had high dissolving power for cellulose. However, in the $\mathrm{NH}_{3}$ system, only the solution of $\mathrm{NH}_{4} \mathrm{SCN}$ was kept liquid state under ambient conditions of temperature and pressure. In the solutions of $\mathrm{NaSCN}, \mathrm{KSCN}$, $\mathrm{NaNO}_{3}$, and $\mathrm{NaI}$ in $\mathrm{NH}_{3}$, the $\mathrm{NH}_{3}$ was rapidly evaporated at ordinary temperatures and pressures due to high volatility of $\mathrm{NH}_{3}$ even though they dissolved cellulose at $-10^{\circ} \mathrm{C}$. This suggests that the strong interactions exist between $\mathrm{NH}_{3}$ and $\mathrm{NH}_{4} \mathrm{SCN}$ molecules through hydrogen bonds and ion-dipole forces. On the other hand, in the $\mathrm{NH}_{2} \mathrm{NH}_{2}$ system, LiSCN, $\mathrm{NaSCN}, \mathrm{KSCN}$, and $\mathrm{NaI}$ were effective but $\mathrm{NH}_{4} \mathrm{SCN}$ was ineffective for dissolving cellulose. Thus, in the amine/salt system, there is a close relationship between physical properties of salt, particularly ionic radius and strength of the interactions with amine, and dissolving power for cellulose. In the present work, the solubility of these thiocyanate salts in ethylenediamine and the dissolving power for cellulose were examined. The results are summarized in Table I.

Of the salts tested, LiSCN and $\mathrm{Ca}(\mathrm{SCN})_{2}$ were commercially obtained as a hydrate form. Both solubilities of the hydrate and anhydrous forms were measured. Multihydrate of LiSCN and $\mathrm{Ca}(\mathrm{SCN})_{2} \cdot 4 \mathrm{H}_{2} \mathrm{O}$ showed high solubility of $174 \mathrm{~g}$ and $152 \mathrm{~g}$, respectively, in $100 \mathrm{~g}$ of ethylenediamine, however, these solutions did not dissolve cellulose at all. It is known that a concentrated $\mathrm{Ca}(\mathrm{SCN})_{2} \cdot 4 \mathrm{H}_{2} \mathrm{O}$ aqueous solution dissolves cellulose above $100{ }^{\circ} \mathrm{C} .{ }^{5}$ Hattori et $a .^{20}$ also showed that cellulose interacts with $\mathrm{Ca}(\mathrm{SCN})_{2} \cdot 4 \mathrm{H}_{2} \mathrm{O}$ in water at the concentration of

Table I. Solubility of salt in ethylenediamine at $25^{\circ} \mathrm{C}$ and dissolution power for cellulose

\begin{tabular}{lcc}
\hline \multicolumn{1}{c}{ Salt } & $\begin{array}{c}\text { Solubility of salt } \\
(\mathrm{g} / 100 \mathrm{~g} \text { of ethylenediamine })\end{array}$ & $\begin{array}{c}\text { Dissolution power for cellulose } \\
(\mathrm{g} / 100 \mathrm{~g} \text { of the solvent })\end{array}$ \\
\hline $\mathrm{LiSCN}$ & 101 & 0 \\
$\mathrm{LiSCN} \cdot n \mathrm{H}_{2} \mathrm{O}$ & 174 & 0 \\
$\mathrm{NaSCN}$ & 86 & 16 \\
$\mathrm{KSCN}$ & 81 & 15 \\
$\mathrm{Ca}(\mathrm{SCN})_{2}$ & 0 & 0 \\
$\mathrm{Ca}(\mathrm{SCN})_{2} \cdot 4 \mathrm{H}_{2} \mathrm{O}$ & 152 & 0 \\
\hline
\end{tabular}

${ }^{a}$ Whatman CC41 Cellulose Powder (DP210) was used. 
$\mathrm{Ca}(\mathrm{SCN})_{2}$ more than $48.5 \%(\mathrm{w} / \mathrm{v})$. They speculated the mechanism of the interaction that the hydration number of $\mathrm{Ca}(\mathrm{SCN})_{2}$ changed from 4 to 2 to form a cellulose- $\mathrm{Ca}(\mathrm{SCN})_{2}-\left(\mathrm{H}_{2} \mathrm{O}\right)_{2}$ complex. In water, the coordinated water molecules in $\mathrm{Ca}(\mathrm{SCN})_{2} \cdot 4 \mathrm{H}_{2} \mathrm{O}$ could be released and replaced to the hydroxyl groups of cellulose at elevated temperatures, while may be little released in ethylenediamine at room temperature. Therefore, the dissolution of cellulose would not be accomplished in the ethylenediamine/ $\mathrm{Ca}(\mathrm{SCN})_{2} \cdot 4 \mathrm{H}_{2} \mathrm{O}$ system. Anhydrous $\mathrm{Ca}(\mathrm{SCN})_{2}$ was not dissolved in ethylenediamine at $25^{\circ} \mathrm{C}$, so that no dissolution of cellulose occurred in the system.

Saturated solutions of NaSCN and KSCN in ethylenediamine, i.e., the systems of ethylenediamine/ $\mathrm{NaSCN} 54 / 46$ (w/w) and ethylenediamine/KSCN $55 / 45(\mathrm{w} / \mathrm{w})$ dissolved cellulose (DP210) with high concentrations of 16 and $15 \%(\mathrm{w} / \mathrm{w})$, respectively. According to the dissolution mechanism of cellulose in the amine/salt system we hypothesized, ${ }^{1}$ it is important to form a salt-amine complex, which is constructed through dipole interaction and/or hydrogen bonding and exists only in the region of high salt concentrations. Further important thing is that at least one amine molecule must be released from the saltamine cluster and replaced to the hydroxyl group of cellulose. The strength of the salt-amine interaction would greatly depend on the ion size of the salt. The size of $\mathrm{Na}^{+}$and $\mathrm{K}^{+}$may be suitable for the formation of the complex with reasonable intensity between salt and amine. This moderate binding of $\mathrm{NaSCN}$ and KSCN with ethylenediamine permits the substitution of ethylenediamine molecule to hydroxyl group of cellulose leading ultimately to the cellulose dissolution.

Generally, solubility of cellulose depends on its molecular weight, crystallinity, polymorph, and crystal size. The molecular weight is an important factor for the physical and mechanical properties of cellulose regenerated from the solutions. Higher molecular weights are advantageous to obtain higher mechanical properties of cellulosic materials. However, there are

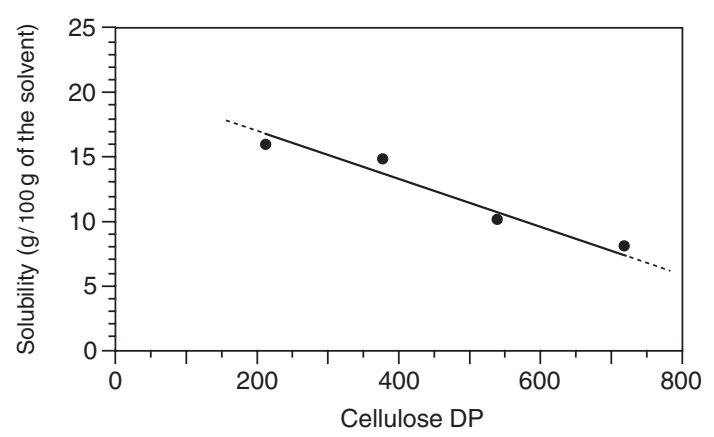

Figure 1. Solubility of cellulose dependent on DP in the ethylenediamine/NaSCN. few reports on the solubility difference between different molecular weights of cellulose. Figure 1 shows the solubility of cellulose dependent on DP in the ethylenediamine/NaSCN 54/46 (w/w). Four celluloses with different DP were used for the measurements. Among them, two were prepared from Cellunier $\mathrm{P}$ (DP716) by acid hydrolysis to give DP536 and 376. The DP210 was from a different source, Whatman CC41. Interestingly, the solubility decreased almost linearly from 16 to $8 \%(\mathrm{w} / \mathrm{w})$ with increasing DP from 210 to 716 even though the solubility of cellulose with different molecular weight can not be compared precisely each other because of their different molecular weight distributions. Matsumoto et al. ${ }^{21}$ investigated the differences in the solubility and solution properties of celluloses from different biological origins such as plants, bacteria, and marine animals in $\mathrm{LiCl} / \mathrm{DMAc}$ solvent. In the ethylenediamine/ $\mathrm{NaSCN} 54 / 46(\mathrm{w} / \mathrm{w})$ system, bacterial cellulose (DP2250) was also dissolved up to $5 \%(\mathrm{w} / \mathrm{w})$ maximum. However, it took $5 \mathrm{~d}$ to attain the complete dissolution. This is presumably due to the high crystallinity and molecular weight.

\section{Chemical Stability of Cellulose in the Ethylenedi- amine/NaSCN System}

The chemical stability of cellulose in the solution is an important criterion for the utilization of any particular cellulose solvent. In regard to this, experiments were conducted to ascertain the stability of cellulose in the ethylenediamine/NaSCN 54/46 (w/w) for a long period of storage. Relative viscosity $\left(\eta_{\text {rel }}\right)$ change was traced in a solution of $1.00 \%(\mathrm{w} / \mathrm{v})$ Cellulose Powder $\mathrm{CC} 41$ at $25^{\circ} \mathrm{C}$ as shown in Figure 2. The viscosity loss was only $2.2 \%$ for $30 \mathrm{~d}$ storage. These diminutive decreases could be caused by, not degradation, but conformational changes of the main chain

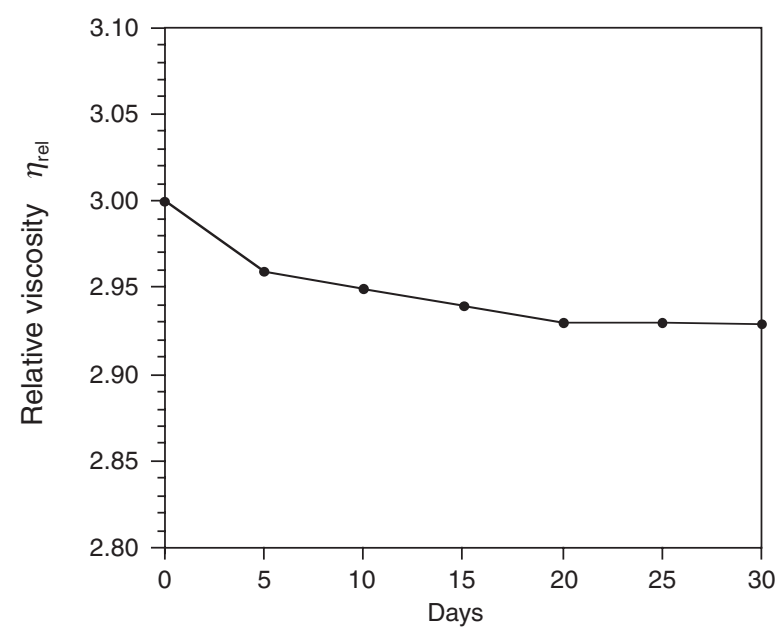

Figure 2. Relative viscosity change of a $1.00 \%$ cellulose solution in the ethylenediamine/ $\mathrm{NaSCN}$. 


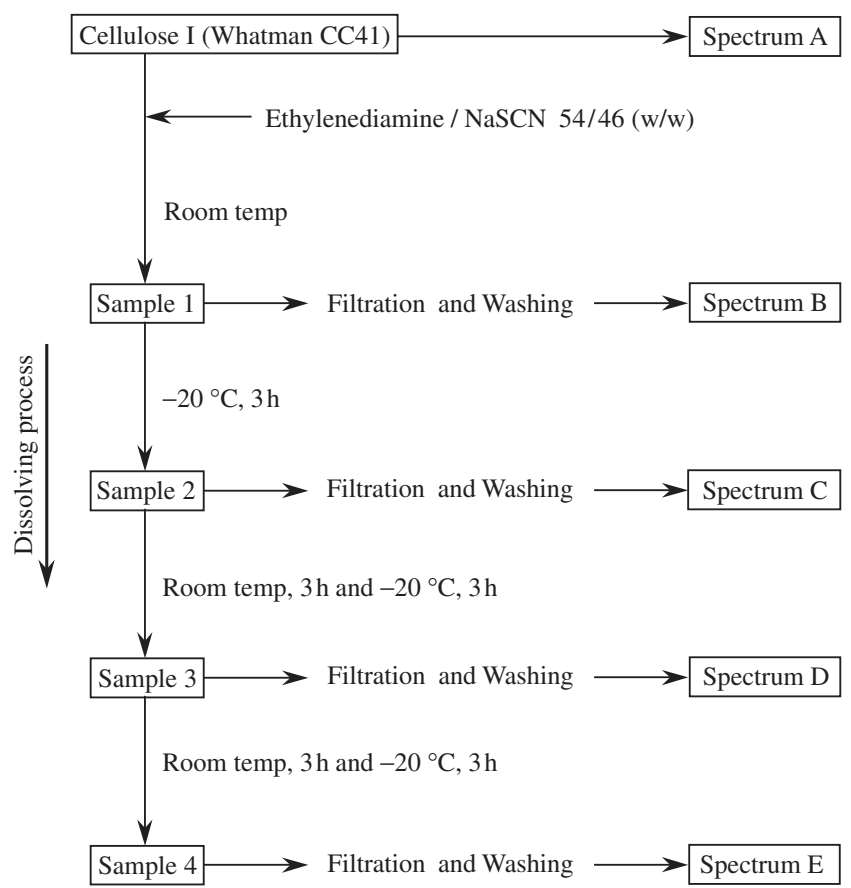

Figure 3. Dissolution process of cellulose in the ethylenediamine/NaSCN subjecting the system to the temperature cycling processes.

due to breaking hydrogen bondings. Slight color change of the solution was observed for $30 \mathrm{~d}$ storage. This yellow tint is a likely result of thiocyanogen arisen from the solvent. It disappeared on additions of small amounts of water. As described later, no thiocyanogen peak appeared in the IR spectrum of the cellulose recovered from the solutions. It is concluded that no significant degradation of cellulose occurred in the ethylenediamine/ $\mathrm{NaSCN}$ solvent for $30 \mathrm{~d}$ storage.

\section{Dissolution Behavior of Cellulose in the Ethylenedi- amine/NaSCN System}

To achieve the dissolution of cellulose, scission of its inter- and intramolecular hydrogen bonds is required. Using the rapid dissolution method for cellulose we have developed, ${ }^{17}$ it could be continuously monitored in a short time by ${ }^{13} \mathrm{C}$ NMR technique to break the hydrogen bondings as well as change the conformations of cellulose during the dissolution process. Figure 3 shows the dissolving process of cellulose involving the temperature cycling between room temperature and $-20^{\circ} \mathrm{C}$. Each temperature was subjected to the system by $3 \mathrm{~h}$. The results of the $\mathrm{CP} / \mathrm{MAS}{ }^{13} \mathrm{C}$ NMR measurements are presented in Figure 4.

Figure $4 \mathrm{~A}$ shows a $\mathrm{CP} / \mathrm{MAS}{ }^{13} \mathrm{C}$ NMR spectrum of Whatman CC41 cellulose powder prior to dissolving in the ethylenediamine/ $\mathrm{NaSCN} 54 / 46$ (w/w) solvent. It is a typical pattern of cellulose $\mathbf{I}$ as the $\mathrm{C} 1, \mathrm{C} 4$, and C6 resonances appeared at 106, 90, and $65 \mathrm{ppm}$, re-

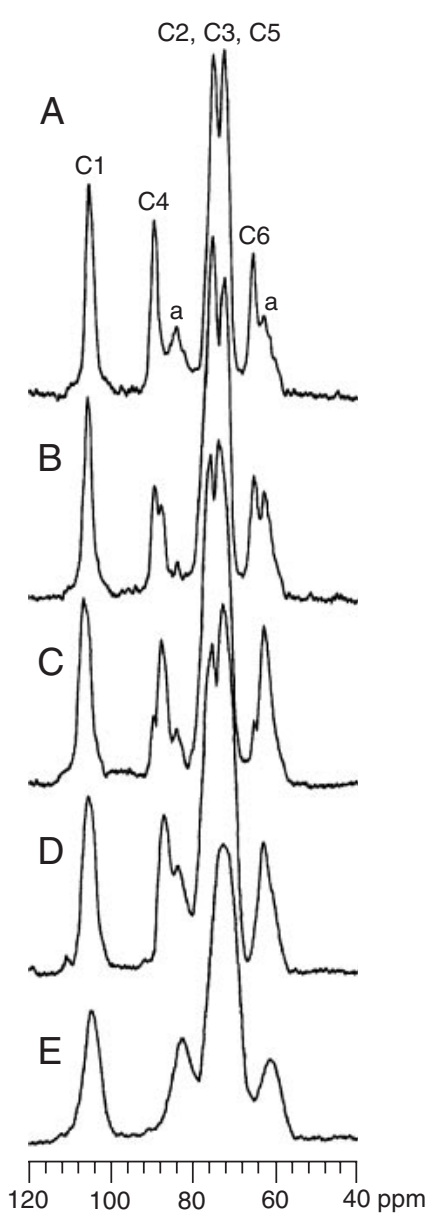

Figure 4. $75 \mathrm{MHz} \mathrm{CP} / \mathrm{MAS}{ }^{13} \mathrm{C} \mathrm{NMR}$ spectra of the cellulose during dissolving process in the ethylenediamine/NaSCN.

spectively. Additionally, two broad peaks appear at ca. 84 and $63 \mathrm{ppm}$ (Marked with a). According to Atalla et al. ${ }^{22}$ these two peaks are derived from the $\mathrm{C} 4$ and $\mathrm{C} 6$ absorptions in the amorphous cellulose, respectively.

After the cellulose I was mixed with the solvent for $3 \mathrm{~h}$ at room temperature, the spectrum of the sample apparently changed as shown in Figure 4B. The intensity of the $\mathrm{C} 4$ peak at $90 \mathrm{ppm}$ decreased and a new peak appeared at $88 \mathrm{ppm}$. It is probable that this new peak resulted from shifting of the $\mathrm{C} 4$ peak at $90 \mathrm{ppm}$ owing to changing the high-order structure of the cellulose I and/or breaking intramolecular hydrogen bond between oxygen of the glycosidic linkage $\left(\mathrm{C} 1-\mathrm{O}-\mathrm{C}^{\prime} 4\right)$ and hydrogen of the hydroxyl group at $\mathrm{C} 2$ position $(\mathrm{C} 2-\mathrm{OH})$ of the cellulose I. Very recently, the occurrence of this type of hydrogen bond was found in cellulose $\mathbf{I}_{\beta}$ by using neutron fiber diffraction. ${ }^{23}$

For the following $3 \mathrm{~h}$ storage at $-20^{\circ} \mathrm{C}$, the intensities of each $\mathrm{C} 4$ peak were reversed (Figure 4C), then, after the second temperature cycling process, the $\mathrm{C} 4$ peak at $90 \mathrm{ppm}$ disappeared entirely (Figure 4D). Similar reversal was observed between C6 peaks. 
As the dissolution process proceeds, the C6 peak at $65 \mathrm{ppm}$ disappeared and the intensity of another C6 at $63 \mathrm{ppm}$ increased. This is probably due to change of the hydrogen-bonding system and/or the chain conformation of the cellulose I. Taking the spectrum pattern and chemical shift of each peak into consideration, it seems that Figure 4D shows a mixture of cellulose III polymorph and amorphous cellulose. ${ }^{24}$ On the other hand, Figure 4E shows exemplary amorphous cellulose as the $\mathrm{C} 1, \mathrm{C} 4$, and $\mathrm{C} 6$ absorptions appeared with relatively broad resonance. From these interpretations in Figure 4, it is concluded that polymorphic transformations from cellulose I to III to amorphous structure and ultimate dissolution occurred as the dissolution process proceeds when cellulose I was mixed with the ethylenediamine/ $\mathrm{NaSCN}$ solvent. It is known that ethylenediamine is a strong swelling reagent for cellulose and converts cellulose I to III polymorph. Therefore, these transformations in Figure 4 seem to be reasonable as the dissolution of cellulose proceeds in the ethylenediamine/ $\mathrm{NaSCN}$ solvent.

\section{Mesophase Formation}

It is of interest that some cellulose solutions form anisotropic phase in a certain solvent, however, others are isotropic even though the same cellulose is used. For instance, cellulose solutions in $\mathrm{LiCl} / \mathrm{DMAc}^{25}$ and $\mathrm{NMMO} / \mathrm{H}_{2} \mathrm{O}^{26}$ solvents exhibit anisotropy under appropriate conditions, whereas there are no reports on the anisotropic solutions of cellulose in $\mathrm{Ca}(\mathrm{SCN})_{2} / \mathrm{H}_{2} \mathrm{O}$. We have also reported liquid-crystalline properties of the cellulose $/ \mathrm{NH}_{3} / \mathrm{NH}_{4} \mathrm{SCN}^{9-13}$ and cellulose $/ \mathrm{NH}_{2} \mathrm{NH}_{2} /$ thiocyanate salt ${ }^{1}$ systems. Thus, the formation of anisotropic phase in the cellulose solutions depends on the solvent component. In the present work, the mesophase formation of the cellulose/ ethylenediamine/NaSCN system was investigated by crossed polars microscopic observations and steadyshear viscosity measurements.
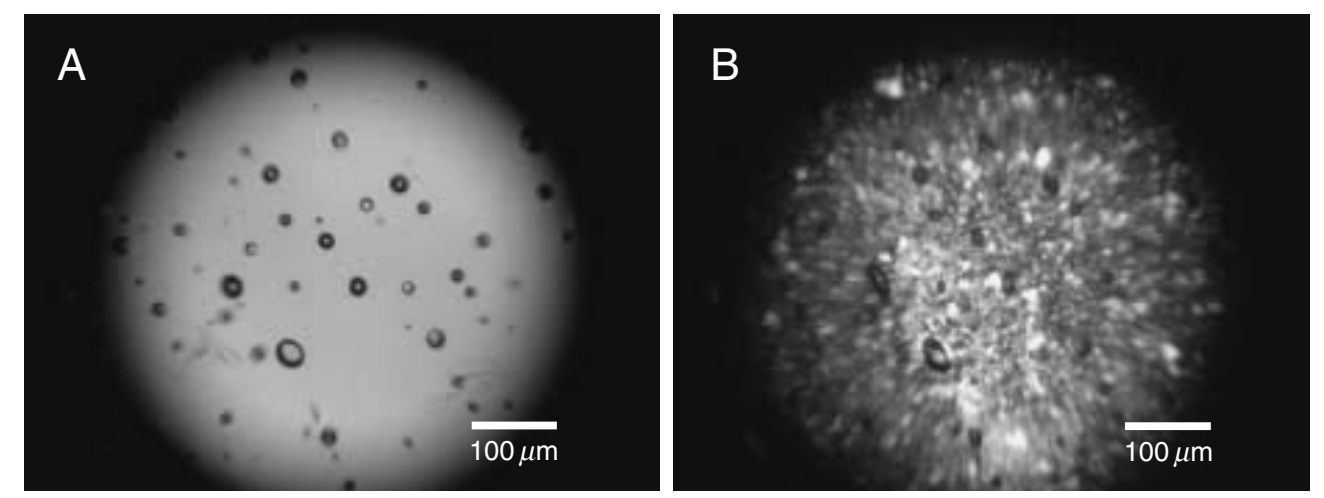

Figure 5. Photomicrographs $(\times 200)$ of a $12 \%(w / w)$ cellulose $(\mathrm{DP} 210)$ solution in the ethylenediamine/NaSCN under non-crossed polars (A) and crossed polars (B). w) cellulose (DP210) solution in the ethylenediamine/NaSCN 54/46 under non-crossed polars (A) and crossed polars (B) at $40^{\circ} \mathrm{C}$. Nothing was observed except for bubbles under non-crossed polars, affording a proof of the complete dissolution of cellulose in the solvent. On the other hand, a pattern of dark and bright textures was observed under crossed polars as shown in Figure 5B. Since a polarizer and analyzer of the microscopy were set to cross nicols, the dark and bright areas demonstrate isotropic and anisotropic regions, respectively. The bright domains appeared initially at $c a .10 \%(\mathrm{w} / \mathrm{w})$ of cellulose concentration and increased with increasing the concentration. This critical concentration suggests that the orienting behavior of cellulose in the ethylenediamine/ $\mathrm{NaSCN}$ is slightly lower than that in the $\mathrm{NH}_{3} / \mathrm{NH}_{4} \mathrm{SCN}^{11}$ and $\mathrm{NH}_{2} \mathrm{NH}_{2} /$ thiocyanate salt ${ }^{1}$ systems. Presently, it is not clear the relationship, if any, between the difference of amine and the critical concentration.

Viscosity behavior of the cellulose (DP210)/ethyl-

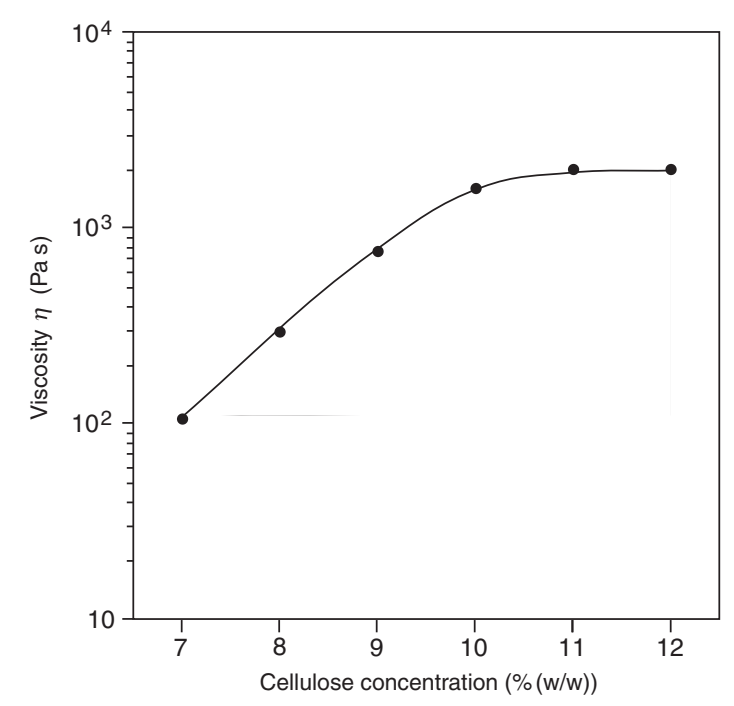

Figure 6. Viscosity of the cellulose solutions in the ethylenediamine/NaSCN $54 / 46$ at $40^{\circ} \mathrm{C}$. 


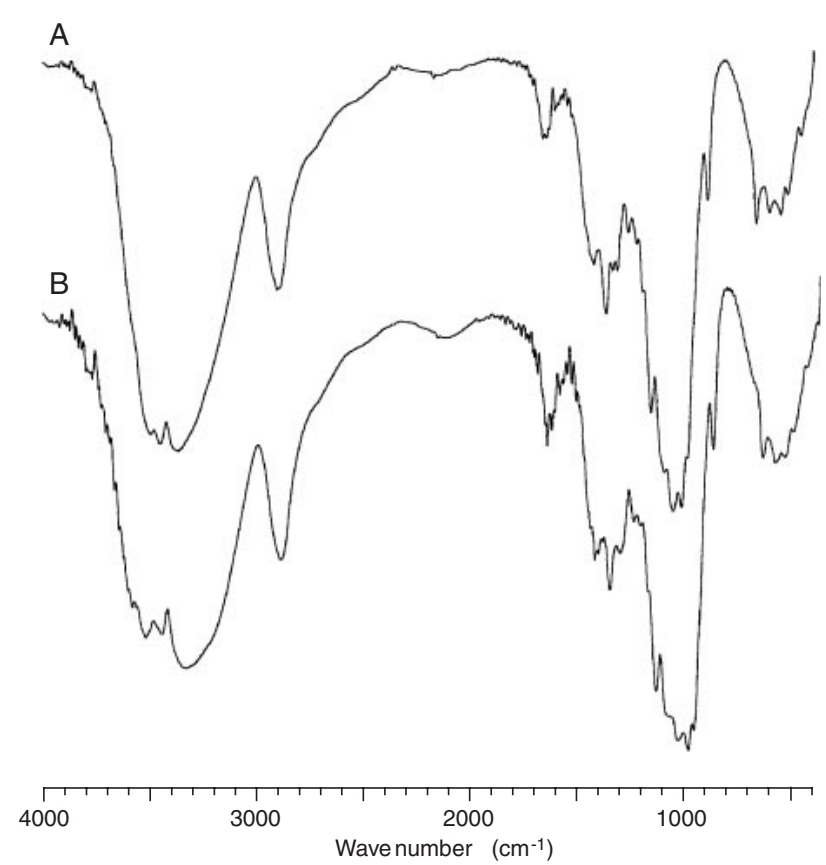

Figure 7. IR spectra of cellulose; (A) Whatmann CC41 and (B) recovered by coagulating the cellulose/ethylenediamine/ NaSCN solution in water.

enediamine/NaSCN solutions is shown in Figure 6 as a function of cellulose concentration. The viscosity was measured at low shear rate of $1.0 \times 10^{-3} \mathrm{~s}^{-1}$ using a cone and plate rheometer. An exponentially rapid increase in viscosity was observed from 7 to $10 \%$ $(w / w)$ of the cellulose concentrations. However, from 10 to $12 \%(\mathrm{w} / \mathrm{w})$, the viscosity was nearly constant despite an increment of cellulose concentration, suggesting that the molecular orientation of cellulose was initiated from $10 \%(\mathrm{w} / \mathrm{w})$. This critical concentration is in agreement with that in the initial appearance of a birefringent region in the crossed-polars microscopic observations.

\section{Recovered Cellulose}

Coagulation and recovery of cellulose from the cellulose solutions are important process for the production of cellulosic fiber and films. Physical and chemical structures of the cellulose recovered from the cellulose/ethylenediamine/NaSCN solution were studied by IR and X-Ray analyses. Figures 7 and 8 represent, respectively, IR spectra and X-Ray diffractograms of the cellulose (A) before dissolving in the solvent and (B) recovered by coagulating the cellulose/ethylenediamine/ $\mathrm{NaSCN}$ solution in water.

In Figure 7, the two spectra are quite similar and no thiocyanate absorption appears around $2200 \mathrm{~cm}^{-1}$ in spectrum $\mathrm{B}$, which indicates that no chemical reaction with the solvent occurred during the dissolution and coagulation processes of the cellulose. The cellulose recovered was white flocculent. The solvent was

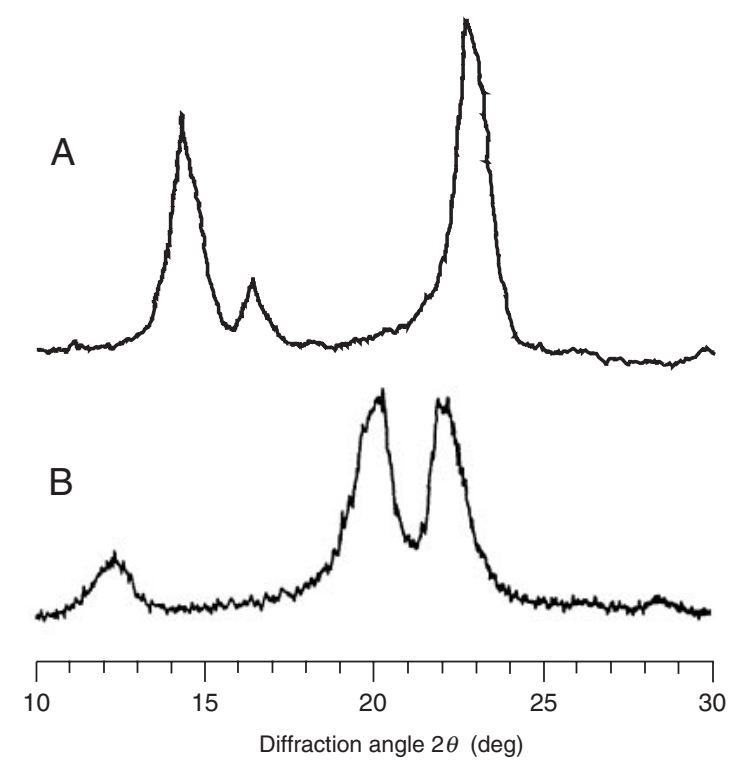

Figure 8. X-Ray diffractgrams of cellulose; (A) Whatmann CC41 and (B) recovered by coagulating the cellulose/ethylenediamine/NaSCN solution in water.

found to be completely eliminated by coagulating and the following enough washing with water.

$\mathrm{X}$-Ray diffractograms in Figure 8 display the polymorphic difference between the celluloses before dissolving and after coagulating with water. The original cellulose, Whatman CC41, was cellulose I as indicated by the diffraction angles $2 \theta$ values $^{27}$ of $14.2^{\circ}$, $16.4^{\circ}$, and $22.6^{\circ}$ in Figure 8A. After dissolution and subsequent coagulation with water, the cellulose recovered was II polymorph with the diffraction angles of $12.3^{\circ}, 20.2^{\circ}$, and $22.1^{\circ 27}$ shown in Figure 8B. This polymorphic conversion is ordinary phenomena in the production of typical regenerated cellulosic fibers such as viscose rayon, cupra, and Tencel ${ }^{\mathbb{R}}$. Interestingly, there are some differences as to the polymorph of cellulose recovered from the cellulose/amine/thiocyanate salt solutions: when ammonia was used as a component of the solvent system, cellulose III was recovered in water, ${ }^{28}$ while the use of hydrazine and ethylenediamine afforded cellulose II after coagulating the solution with water. Furthermore, in the cellulose/ethylenediamine/NaSCN solution, other coagulants such as methanol, 2-propanol, and acetone brought about the amorphous cellulose. From these results, water seems to be preferred as a coagulant for the formation of high-performance cellulosic materials recovered from the cellulose/ethylenediamine/ NaSCN solutions.

\section{CONCLUSION}

The ethylenediamine/thiocyanate salt system was discovered to be a good solvent for cellulose. The salts, NaSCN and KSCN were effective, while LiSCN 
and $\mathrm{Ca}(\mathrm{SCN})_{2}$ were ineffective in both hydrate and anhydrous forms. The ionic radius of the salt as well as the size of amine are apparently the most important factor for the solubilization of cellulose in the amine/ salt system. The maximum solubility reached $16 \%$ $(\mathrm{w} / \mathrm{w})$ for the cellulose of DP210 in the ethylenediamine/NaSCN 54/46 (w/w), and decreased linearly with increasing cellulose DP. Bacterial cellulose was also dissolved, but, it took $5 \mathrm{~d}$ to obtain complete dissolution. All cellulose dissolutions took place at room temperature, and the cellulose dissolved was chemically stable for $30 \mathrm{~d}$ storage at room temperature.

The CP/MAS ${ }^{13} \mathrm{CNMR}$ measurements disclosed the polymorphic conversion of cellulose in the dissolving process. When cellulose I was dissolved in the ethylenediamine/NaSCN system, the polymorph was transformed from I to III to amorphous structure as the dissolution process proceeds. This behavior was different from that in the $\mathrm{NH}_{3} / \mathrm{NH}_{4} \mathrm{SCN}$ system.

Microscopic observations and steady-shear viscosity measurements showed mesophase formation of the cellulose/ethylenediamine/NaSCN system. The anisotrpoic phase appeared from $c a .10 \%(\mathrm{w} / \mathrm{w})$ of cellulose with DP210 and greatly depended on the cellulose concentrations. This critical concentration was slightly lower than those in the $\mathrm{NH}_{3} / \mathrm{NH}_{4} \mathrm{SCN}$ and $\mathrm{NH}_{2} \mathrm{NH}_{2} / \mathrm{NaSCN}$ systems. Coagulation studies disclosed that cellulose II and amorphous cellulose were recovered from the cellulose/ethylenediamine/thiocyanate salt solutions when water and alcohol were used as a coagulant, respectively. This system is a promising solvent for cellulose which is environmentally favorable, low cost, low toxicity, needs neither heating nor pretreatment of cellulose, and provides liquid-crystal formation.

Acknowledgment. This work was partly supported by a Grant-in-Aid for Young Scientists (B) (No. 14750702) of The Ministry of Education, Culture, Sports, Science and Technology (MEXT).

\section{REFERENCES AND NOTES}

1. K. Hattori, J. A. Cuculo, and S. M. Hudson, J. Polym. Sci., Part A: Polym. Chem., 40, 601 (2002).

2. For example, K. Hattori, in "Kirk-Othmer Encyclopedia of Chemical Technology," 3rd Ed., J. Kroschwitz, Ed., John Wiley \& Sons, Hoboken, N.J., 2003, Chapter on Cellulose.

3. T. R. Dawsey and C. L. McCormick, J. Macromol. Sci.Rev. Macromol. Chem. Phys., C30, 405 (1990).

4. H.-P. Fink, P. Weigel, H. J. Purz, and J. Ganster, Prog. Polym. Sci., 26, 1473 (2001).

5. A. Dubosc, Bull. Soc. Ind. Rouen, 33, 318 (1905).

6. R. P. Swatloski, S. K. Spear, J. D. Holbrey, and R. D.
Rogers, J. Am. Chem. Soc., 124, 4794 (2002).

7. J. A. Cuculo and S. M. Hudson, U.S. Patent 4367191 (Jan. 4, 1983).

8. N. Aminuddin, MS Thesis, Department of Textile Engineering, Chemistry, and Science, North Carolina State University, 1993.

9. Y.-S. Chen and J. A. Cuculo, J. Polym. Sci., Part A: Polym. Chem., 24, 2075 (1986).

10. C. R. La Marre, J. A. Cuculo, S. M. Hudson, and A. Ciferri, Mol. Cryst. Liq. Cryst. Lett., 7, 193 (1991).

11. A. W. De Groot, D. E. Guinnup, M. H. Theil, and J. A. Cuculo, J. Polym. Sci., Part B: Polym. Phys., 29, 557 (1991).

12. K.-S. Yang, J. A. Cuculo, and M. H. Theil, J. Polym. Sci., Part B: Polym. Phys., 30, 315 (1992).

13. M. W. Frey, J. A. Cuculo, and R. J. Spontak, J. Polym. Sci., Part B: Polym. Phys., 34, 2049 (1996).

14. J.-X. Guo and D. G. Gray, in "Cellulosic Polymers, Blends and Composites," R. D. Gilbert, Ed., Hanser, Munich, 1994, Chap 2, pp 25-45.

15. ASTM Method D4243, in "Annual Book of ASTM Standards," American Society for Testing and Materials, Philadelphia, P.A., 1999.

16. ASTM Method D1795, in "Annual Book of ASTM Standards," American Society for Testing and Materials, Philadelphia, P.A., 1999.

17. J. A. Cuculo, C. B. Smith, U. Sangwatanaroj, E. O. Stejskal, and S. S. Sankar, J. Polym. Sci., Part A: Polym. Chem., 32, 241 (1994).

18. P. C. Scherer, J. Am. Chem. Soc., 53, 4009 (1931).

19. S. M. Hudson and J. A. Cuculo, J. Polym. Sci., Polym. Chem. Ed., 18, 3469 (1980).

20. M. Hattori, T. Koga, Y. Shimaya, and M. Saito, Polym. J., 30, 43 (1998).

21. T. Matsumoto, D. Tatusmi, N. Tamai, and T. Takaki, Cellulose, 8, 275 (2001).

22. R. H. Atalla, J. C. Gast, D. W. Sindorf, V. J. Bartuska, G. E. Maciel, J. Am. Chem. Soc., 102, 3249 (1980).

23. Y. Nishiyama, P. Langan, and H. Chanzy, J. Am. Chem. Soc., 124, 9074 (2002).

24. The C1, C4, and C6 peaks of cellulose III and amorphous cellulose appear typically at 105,88 , and $63 \mathrm{ppm}$ and 105 , 84, and 63 ppm, respectively; see A. Isogai, M. Usuda, T. Kato, T. Uryu, and R. H. Atalla, Macromolecules, 22, 3168 (1989).

25. For example, E. Bianchi, A. Ciferri, G. Conio, A. Cosani, and M. Terbojevich, Macromolecules, 18, 646 (1985).

26. H. Chanzy and A. Peguy, J. Polym. Sci., Polym. Phys. Ed., 18, 1137 (1980).

27. A. Isogai, in "Cellulosic Polymers, Blends and Composites,” R. D. Gilbert, Ed, Hanser, Munich, 1994, Chap 1, pp 1-24.

28. J. A. Cuculo, N. Aminuddin, S. M. Hudson, and A. V. Wilson, in "Polymeric Materials Encyclopedia," J. C. Salamone, CRC Press, Boca Raton, F.L., 1996, vol 2, pp 1029-1035. 